\title{
Development And Validation Of A Diagnosis And Evaluation Instrument For Non-Governmental Organizations: Indicators To Determine Strengths, Weaknesses, And Areas Of Opportunity As A Means To Improve NGOs' Performance
}

Adriana Martínez Guerrero, (E-mail: adrianamartinezguerrero@yahoo.com), Universidad Anáhuac del Sur, México

\begin{abstract}
Currently, there are many effectiveness and efficiency theories, models and indicators in the companies worldwide. These theories, models, and indicators are more frequently applied to increase productivity and improve product and/or service quality. However, most nongovernmental organizations (NGOs) in Mexico lack the necessary administrative structure to achieve a correct performance. NGOs help, to a large extent, improve the quality of life of many people in the developing countries, but the lack of tools has prevented NGOs from achieving their best performance (regarding productivity, efficiency, and transparency). The former can diminish reliability from the potential donors. A little has been done regarding NGOs' administrative management in Mexico. The little existing research is mainly based on aspects such as NGOs history, experience, and current situation. Experts still expect other people, through formal studies, to complete this research to provide NGOs with the necessary tools to achieve the sector expected growth. The purpose of this research is to provide the tools that this type of organizations need to increase their performance level and improve credibility to attain their social objectives.
\end{abstract}

\section{INTRODUCTION}

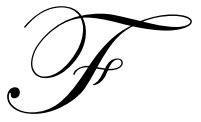

or the companies, adopting international standards translates into developing products and/or services in different sectors under the worldwide accepted specifications and gives them the opportunity to compete at an international level.

It is important to mention that although these standards are not mandatory, they were created as a response to the market demands and are based on consensus among the stakeholders. Applying these standards is considered a requirement to survive in a globalized world.

Currently, over 500,000 companies in more than 60 countries are implementing ISO 9000, which lays down a frame of reference for the quality standards during all the good and/or service production process. On the other hand, ISO 14000 refers to environmental standards and this certification is helping out all types of organizations improve their environmental performance and, at the same time, have a positive impact in the results. (www.iso.org)

Standards and measurements are not unknown for the companies (Foreign and domestic) that want to outstand for their excellence in their own markets. 
In addition, and in a different context, the Mexican Center for Philanthropy, (CEMEFI, for its acronym in Spanish), along with some Mexican business associations established the Business Social Accountability program, which grants the ESR emblem. This program is a resource for the companies in Mexico to consolidate their market strategies and link the business mission with different social causes. This program encourages companies to develop social accountability practices.

As it is indicated by the name, the purpose of this initiative is to strengthen the business philanthropic culture in Mexico and implement a standard that can allow the companies, based on objective criteria, measure and compare their performance on yearly basis in order to improve it. It is important to mention that the ESR is not mandatory. It is a self-evaluation process carried out by the companies that want to be certified with the ESR or renew it. These companies are aware that socially accountable companies have a competitive advantage, since the market recognizes them and consumers choose them.

Not only will large companies be competing for this emblem, but also small and medium-size companies will be able to obtain it, since being a socially accountable company is not exclusive to large consortiums.

There are performance diagnosis and assessment measures, but we need to reflect and analyze the following question: which are the measurement mechanisms available for the non-Governmental Organizations?

In order to answer this and other questions, first, it is necessary to explain what non-governmental organizations (NGOs) are. According to the United Nations, "a NGO is any non-profit-making group of citizens that is organized locally, nationally or internationally to perform tasks that are directed by people with a common interest". (www.un.org)

NGOs perform a series of humanitarian services and functions. They state the citizen problems to the governments, supervise the policies and encourage community participation, provide analysis and experience, supply mechanisms of early assistance, and help implement international agreements. Some NGOs are focused on specific topics such as human rights, environment, or health. The relationship of non-governmental organizations with the UN offices and agencies depends on the NGO's goals, location, and term of office. As it can be seen, these organizations want to find true solutions to the deficiencies affecting important sectors of the population. They have well-defined objectives and mission, but they also have a common problem: Not all NGOs can be part of the UN system due to their size or lack of administrative and process structure, but even worse, they have little credibility in addition to the lack of philanthropic culture in some countries where they operate. In Mexico, the organization responsible for NGOs is the Mexican Center for Philanthropy (CEMEFI), which, besides coordinating them, provides consultancy and support to attain each of the NGOs' goals.

In fact, in February, 2005, CEMEFI will hold the First Member Forum 2005. The purpose of this forum will be to present the institutionalization and transparency indicators that are promoted to participate in the accreditation process.

Presently, only some regulation and transparency indicators have been considered. It is necessary to establish a comprehensive approach for performance evaluation of non-profit-making organizations.

The purpose of Peter Druker in his first book, "The Concept of Corporation", (Drucker 1993) was to conceive a company as a social system and not only as an economic organization. If his work is placed within the trail of the human relationship movement and ideology around the systems, the organizational development approach will be found. However, Michael Porter in his book "Competitive Strategy" (Porter 1998) was the author that introduced concepts such as the five competitive strengths that determine the appeal of each sector.

In any case, the ideological platform in connection with the strategy does not start or end with Porter. In general, the approaches focused on strategic planning have evolved to more global and flexible strategic management. We cannot forget to mention in this section The Mind of the Strategist (Ohmae 2000), whose author insists on the importance of common visions like the Japanese experience, where consensus and continuous improvement are key 
concepts. In addition, the term reengineering, coined in the 80's, became popular with the book "Reengineering the Corporation" (Champ \& Hammer 2000), whose authors proposed that rather than paying attention to the tasks, we should look after the complete processes to improve the organization operation.

These are only some examples of the existing tools that allow us to evaluate, correct, and channel the efforts of the organizations to attain their goals. This takes us back to the following reflection:

It is necessary to adapt the different administrative approaches to achieve their effective application in the nongovernmental organizations.

Not only should the measuring work be real and sustainable for a certain period of time, but obtaining and keeping those measures should be publicly acknowledged. Keeping certain standards (periodically evaluated) should be a precedent for such organizations if they expect large corporate donors and the public in general to get into the habit of granting them resources.

It is important to highlight that the effectiveness of the organizations to attain their goals should be evidence of their efficiency to meet their objectives, along with the mechanisms used to achieve them. By meeting the effectiveness and productivity parameters, these organizations will show their sponsor that the causes pursued by the NGOs are as good as the mechanisms used to meet them. In a country where philanthropy is conceived as a privilege of the elite than a citizen responsibility, this could be the starting point for Mexico to become a society that permanently supports the less fortunate, and not only as it is done today, but in specific occasions.

The purpose of this research project is to offer to the non-governmental organizations the necessary tools to achieve a better performance index under the productivity, effectiveness and transparency indexes. This process will be explained further in this document.

The main problem that this study deals with is that most non-governmental organizations in Mexico and Latin America have lacked an adequate management approach since, according to the experts' opinion, their performance has been based on good intentions rather than on effective administrative management, in addition to the lack of organizational culture that could foster their professionalization. This problem has deeply affected their credibility and sustainability and has reduced the possibility of raising funds and resources, which directly affects the performance of their social objectives.

\section{METHODOLOGY}

The management approach for this research will be an evaluation and diagnosis approach that will assess transparency, effectiveness, and productivity of such organizations to improve their performance; consequently, it will provide more credibility and more capability to raise funds to attain their social objectives. It is important to mention that it is a continuous improvement process, this is, the non-governmental organizations will have to adopt this process on permanent basis so that the positive results can be kept and become indicators that will be periodically reviewed. following:

After the preliminary exploratory research, some questions emerged, and this research will try to answer the

- Is there an index that can allow the NGOs to evaluate the effectiveness, transparency, and productivity?

- Which is the main current issue in the NGOs' management?

- What are the measurement mechanisms to evaluate the NGOs' performance?

- How can they measure their management and productivity processes and the way to achieve their objectives?

- $\quad$ Can the existing administrative management models be adapted to the NGOs?

- How can these organizations optimize their resources to achieve more benefits for their users?

- How can the donors and/or sponsors' trust be improved so that they can invest in this type of organizations? 
- How can this contribute to the development of the NGOs so they can be more involved in the social dynamics?

To answer these questions, we have established the main objective of this research as follows: establish administrative management elements to improve the non-governmental organizations' performance by adapting the existing tools to identify the internal and external areas of opportunity regarding productivity, effectiveness, and transparency through the creation and validation of a diagnosis and evaluation instrument.

It is important to mention that, although it is not the main objective, this research will try to have a bearing on the society culture to transform it from a "not very participative society" to a "permanent supportive society"; in other words, this project will try to improve the philanthropic culture in Mexico in the long term.

The following specific objectives derive from the general objective:

- $\quad$ Provide the non-governmental organizations with the necessary tools to improve their performance and improve the donors and sponsors' trust to make it easier for them to get financial resources.

- $\quad$ Help NGOs optimize the resources received to better support their beneficiaries.

- $\quad$ Foster NGOs' professionalization.

- Boost attainability of each NGO's social mission.

- In the long term, foster the Mexicans' commitment towards the existing needs and attain a deeper philanthropic culture.

It is possible to develop an instrument to measure in a valid and reliable way the administrative management of the non-governmental organizations based on the effectiveness, transparency, and productivity indicators. This instrument will be able to identify the internal areas considered strengths and weaknesses, and internal and external areas of opportunity by using an appropriate administrative approach to analyze and diagnose in order to provide conclusions, recommendations, and suggestions to improve performance. If a non-governmental organization has a better administrative infrastructure based on specific characteristics, it will improve its performance, and this will be translated into a better use of the resources to achieve its social objectives".

Some of the operating hypotheses are the following:

H1: Establishing measurement indicators will improve the performance of the non-governmental organizations regarding effectiveness, productivity, and transparency.

H2: Providing a diagnosis and evaluation of the strengths, weaknesses, and areas of opportunity will help the organizations detect their problems and create the necessary solutions.

H3: Improving the non-governmental organizations' credibility will provide them a better capability to get financial resources from the sponsors or donors.

In this research, indicators ${ }^{1}$ applied to organizations in Mexico and abroad will be analyzed to adapt them to the specific needs of the non-governmental organizations in Mexico. The performance of the organizations under study will be evaluated through the effectiveness, productivity and transparency indicators.

Regarding the approach of this research, effectiveness will be evaluated based on the non-governmental organizations' ability to select feasible projects that can show in the short term their capability to solve social problems and positively affect a larger number of persons. Productivity will be measured based on the existing relationship between the organization's inputs (financial, human, and material resources) and outputs, this is, the scope in connection with the beneficiaries and performance of the social objectives.

\footnotetext{
${ }^{1}$ Explanatory note: Operationally, an indicator is the unit that allows us to measure the scope of a goal. However, the relationship between indicator and goal is probabilistic and not logical. Therefore, it is advisable to increase the number of indicators of a goal to increase the probability of obtaining the right measurement. (Cohen \& Franco 2003: Pp. 155-156).
} 
In this research, transparency is formed by references that allow any person, company or institutions identify with certainty the characteristics of a non-governmental organization, including financial and fiscal information, activities, and number of beneficiaries.

\section{DEVELOPMENT}

Research, supported on exploratory and descriptive studies, will be causal, since it will analyze the causeeffect relationship between the measurement indexes and the performance of the organizations under this study. The validation of the instrument will be provided through an experimental design and, based on the results derived from its application, its effectiveness will be evaluated, and the hypothesis will be proven. We will start with an exploratory research with a qualitative approach with regards to the non-governmental organizations' situation in connection with productivity, effectiveness, and transparency, including the economic (financial and fiscal resources), technological, human, infrastructure and facility, knowledge and quality resources.

In this exploratory research the bibliographic information, books, articles and previous research, will be analyzed to determine the status of these topics and determine the foundations for the empiric work or field research. Currently, this research is being supported by Indesol ${ }^{2}$ personnel in collecting the necessary information to identify the specific needs regarding effectiveness, productivity, and transparency of the organizations this institution deals with.

In addition, the experts of the Mexican Center for Philanthropy are providing feedback with regards to the information collected in the exploratory research. Based on the information of the theoretical framework and the information from the experts, the indicators that will be used to create the measurement instrument will be defined. Once the indicators are defined, the first instrument will be created. Such instrument will be subjected to one or several pilot tests (depending on the results) to make the necessary adjustments for its implementation.

After performing the pilot tests and making the necessary adjustments, we will have a measurement instrument that will be validated through an experimental design. As soon as the instrument has been experimentally validated, it will be applied to collect evidence by means of a pre-test design with diagnosis and pos-test design with diagnosis. Afterwards, the effectiveness of the instrument will be evaluated based on the information collected in the experimental phase. The information will be analyzed and the research hypothesis will be proven. This research will end with the conclusions where the research results will be described and the internal and external strengths, weaknesses, and areas of opportunity of these organizations will be explained.

As mentioned in the hypothesis section, the indicators that will be evaluated in this study are the following:

\section{- $\quad$ Productivity \\ - $\quad$ Transparency \\ - $\quad$ Effectiveness}

These indicators were chosen based on the expert requirements, since, as they state, these three elements together will help these organizations have a higher performance. It is important to mention that such indicators may not have a certain relationship, but if any of these indicators were absent in these organizations, it would be very hard to consider them high-performance companies.

Data collection started during the preliminary exploratory research, where the existing directories of nonprofit organizations were studied and the experts were interviewed. They were actually very excited about the topic and possible scope of this research. Based on the information collected from the specialized directories and previous research, the current situation of the non-governmental organizations in Mexico will be determined and the research universe will be defined. In addition, the size of the sample will be established in accordance with a statistical basis. The characteristics of each organization under study will be included in the initial data collection. This is, a diagnosis

\footnotetext{
${ }^{2}$ Explanatory note: Indesol is the National Institute of Social Development in Mexico. It is the government institution responsible for providing support to the non-governmental organizations.
} 
of each organization will be made to have a frame of reference or comparison before and after the instrument was applied. Final data collection will be carried out after the measurement instrument has been applied to have a final diagnosis of the performance achieved by the organizations under this study.

Based on the difference between the performances before and after the instrument was applied, the effectiveness will be analyzed, the hypothesis will be proven, and conclusions and recommendations will be provided so that the performance improvement can be sustained for a long period of time. Surveys will be used to collect and analyze information. We will be very cautious with the information coming from these surveys. This information will be processed by means of statistical software such as SAS, Minitab or SPSS.

Next is a chart of the research design:

\section{Research Design}

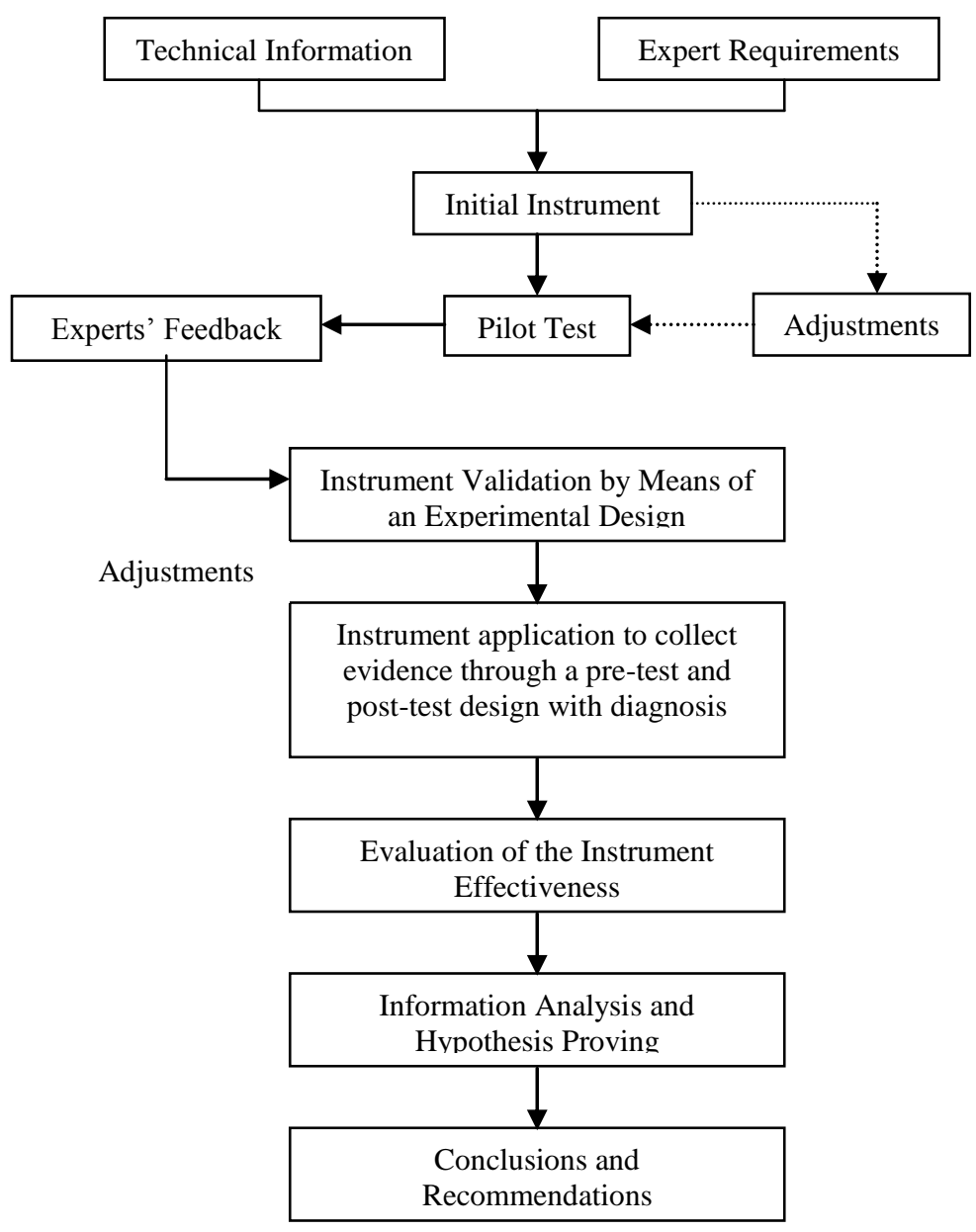




\section{EXPECTED RESULTS}

The scope of this research will be based on the diagnosis and evaluation of the non-governmental organizations registered in the list of authorized donees from the Secretaría de Hacienda y Crédito Público, Treasury Department, (SHCP, for its acronym in Spanish) in Mexico City. Based on such universe of organizations, the size of the sample will be defined to carry out the field work. This approach, where only such organizations will be included, will make it easier to delimit such a broad field, since it sets the necessary boundaries. Furthermore, this is justified because only the organizations with total access to their information will be part of this study. The field research will be carried out (with the most representative samples if possible) in three Spanish-speaking countries in order to have an international scope.

As mentioned in the objective section, one of the purposes of this research is to foster the philanthropic culture in Mexico in a long term, although, because of time constraints, this will have to be evaluated in future research. Through the observation and interviews with experts, a clear need has been detected in the philanthropic field: in order to improve the philanthropic system in Mexico, it is necessary to professionalize such institutions. In previous research and books specialized in this topic, there is interest in doing further research with regards to nongovernmental organizations, especially in aspects related to administrative management. Some examples are the following:

When one wonders where to start so that the Mexican philanthropic system takes on more differentiated dimensions, one bumps into a vicious circle that moves continuously in three axes: lack of proper regulation because of the lack of professionalization; lack of professionalization because of the lack of funding; lack of funding because of the lack of information; lack of information because of the lack of professionalization and funding. (Cemefi 1993: p. 180).

The context where the non-profit-making organizations of social nature perform has made them face up to certification, homologation, or accreditation processes, which have gradually become more standardized. According to our opinion, this has forced the voluntary organizations of social intervention to become more involved in research and development of quality assurance or assessment and, in general, to develop arguments and technologies promoting perceived quality and technical quality in accordance with the specific characteristics of their social intervention. (Fantova 2001: p. 141)

\section{BIBLIOGRAPHY}

1. Barber Kuri, Carlos Miguel. (2005). Megatendencias. En Revista Integra. No. 6. Universidad Anáhuac del Sur. México.

2. Barber Kuri, Carlos Miguel. (2005). Industrias Representativas de América, Europa, y Asia. Ed. Miguel Ángel Porrúa-UAS. México.

3. Barber Kuri, Carlos Miguel. (2005). Casos Empresariales. Tomo II. Ed. Miguel Ángel Porrúa -UAS. México.

4. Centro Mexicano Para La Filantropía. (1993). La Filantropía Mexicana: Diagnóstico y Propuestas. México: CEMEFI.

5. Champy, James y Hammer Michael. (2000). Reingeniería. México: Editorial Norma.

6. Cohen, Ernesto y Franco, Rolando. (2003). Evaluación de Proyectos Sociales. $6^{a}$ Edición. México: Siglo Veintiuno Editores.

7. Drucker, Peter. (1993). The Concept of Corporation. EUA: Harper \& Row Publishers, Inc.

8. Fantova, Fernando. (2001). La gestión de las organizaciones no lucrativas. España: Editorial CCS.

9. Martínez Guerrero, Adriana, Barber Kuri, Carlos Miguel, y Rojas Cataño, Lourdes. (2004). Recursos Humanos. Notianfeca. No. 89. México.

10. Porter, Michael E. (1998). Competitive Strategy: Techniques for analyzing industries and competitors. USA: The free Press.

11. Ohmae, Kenichi. (2000). La mente del estratega. México: McGraw Hill.

12. Robbins, Stephen y Coutler, Mary. (2005). Administración. 8a. Edición. México: Pearson Education. 
13. Verduzco Igartúa, Gustavo. (2003). Organizaciones no lucrativas: visión de su trayectoria en México. México: El Colegio de México, Centro de estudios sociológicos y CEMEFI.

\section{NOTES}

